\title{
As multiracionalidades no contexto da organização escolar
}

\author{
Maria João Carvalho \\ Universidade de Trás-os-Montes e Alto Douro, Portugal
}

Resumo

O estudo das racionalidades nas organizações educativas, em particular na escola, tem como pano de fundo a problemática das decisões na educação e no ensino e a identificação dos interesses, lógicas e objectivos que lhes estão subjacentes. A recusa de uma concepção monista e absoluta de racionalidade coloca-nos perante a possibilidade de distinguirmos entre várias formas de racionalidade. Este objectivo pressupõe uma abordagem multifocalizada no estudo da escola considerando, em termos analíticos e de modo articulado, os modelos burocrático e anárquico, e arquitectando um aparelho conceptual que se articule com a proposta de estudo das multiracionalidades que incorporam as decisões que revelam diferentes formas de poder.

\section{Palavras-chave}

Decisões; Racionalidade burocrática; Multiracionalidades

\section{Introdução}

Os estudos contemporâneos sobre a administração e organização da escola têm colocado a problemática da decisão num lugar de destaque pelo facto de ser considerada um elemento essencial e uma actividade nuclear à qual estão subordinadas todas as demais actividades que se realizam na escola. Quanto mais a descentralização educativa, a autonomia da escola e a participação democrática são discutidas e reivindicadas, mais a problemática da decisão ganha protagonismo, porque decidir é o seu corolário, é o que dá 
visibilidade prática a tais noções. Por ser considerado uma prática que ajuda à construção de homens e mulheres intervenientes, capazes de fazerem parte activa do mundo a que pertencem, ao invés de seus meros espectadores, o exercício da decisão constitui-se como um direito do qual ninguém deve ser privado. Uma reivindicação de sempre que viria a ser formalizada, em prol de uma escola democrática, pela política educativa depois de 25 de Abril de 1974 e que terá o seu momento alto, em termos discursivos, com o Decreto-Lei ${ }^{\circ}$ 115-/98, que o Decreto-Lei 75/2008 viria reforçar. Porém, a máquina burocrática tem sido um entrave a esse propósito em grau semelhante aos interesses da classe política que deixa de estar susceptível à democratização do poder assim que o conquista, porque isso significará sempre uma limitação do seu poder ${ }^{1}$. A prática tem demonstrado o quão difícil é realizar uma reforma de âmbito de governação democrática ${ }^{2}$ pelo não envolvimento da escola na definição das suas próprias políticas e conservando-se uma administração centralizada e autocrática. O presente parece reafirmar a dificuldade em substituir estruturas administrativas ao mesmo tempo que confirma a quase natural tendência para recuperar padrões burocráticos supostamente em vias de desaparecerem. Por isso, a luta que se trava na escola é entre o constrangimento e a autonomia, entre a domesticação que as decisões impostas autoritariamente veiculam, apesar da neutralidade de que se arrogam, e a emancipação que as decisões partilhadas, fundadas na prática da liberdade e longe da neutralidade, possibilitam, mas que, contrariamente às primeiras, implicam mais tempo, envolvem, genericamente, mais recursos, mais tensões, mais discordâncias e menos soluções óptimas, trazendo, em simultâneo, mais responsabilidade, tanto social como política (Freire, 1967: 88), verdadeiro exercício de cidadania e única forma de nos constituirmos enquanto sujeitos democráticos.

\section{A racionalidade das decisões burocráticas}

A actual escola pública portuguesa, ao nível do ensino secundário, não pode ser estudada à margem de um contexto de centralização, seja de âmbito político ou administrativo, que legitima o sistema educativo único e a sua maneira unívoca de administração, criando uma homogeneidade pouco favorável a princípios autonómicos, e à diversidade que compreende, que a possam corromper, ao mesmo tempo que se "alheia" das dificuldades que o 
seu gigantismo origina. Parece que o importante é mesmo o controlo políticoadministrativo, atitude que reflecte a indiferença a que é votada a autonomia das escolas portuguesas, legalmente instituída desde 3 de Fevereiro de 1989 a partir do Decreto-Lei $n^{\circ} 43 / 89$, e que a imagem da burocracia é capaz de difundir.

Estarmos seguros de que a burocracia, enquanto conceito unitário, empenhada na racionalização, não conquistou os seus intentos no que respeita à administração pública portuguesa ${ }^{3}$, não invalida que, enquanto modelo de dimensões, nos possibilite reconhecer aspectos importantes, dos quais salientamos a já supracitada centralização e a instrumentalização que as suas decisões compreendem, o controlo que as normas de uso universal e uniforme veiculam e de que pode ser exemplo o modo como se resolve o problema do abandono escolar, insinuando-se que tem as mesmas causas e os mesmas soluções em todas as escolas ao aplicar-se uma legislação em vigor com "penalizações previstas" para o efeito. Do mesmo modo para a indisciplina, que, regulamentada, acaba por transferir para uma "instância complementar" a resolução da violência insensível a questões do foro psicológico, social ou cultural, transformando a indisciplina num acto reflexo. Uma lógica que é capaz de tornar o ensino em "um sistema mais rígido de controlo", de acordo com as palavras proferidas em entrevista por um anterior ministro da educação. Um controlo incluso na centralização e na produção de normativos que têm a pretensão de tudo contemplar, pois o burocrata da educação acredita estar efectivamente habilitado a prever todos os gestos, todos os movimentos e intervenções do professor, numa tentativa de racionalização óptima - aspecto revelador de uma administração altamente burocrática.

Mais do que assumir este inegável controlo burocrático centralizado, importa perceber o alcance e os objectivos que subjazem a um tipo de orientação que se denuncia por reproduzir uma orientação dominante, usando da uniformidade e da universalidade para efectivar a sua imposição. Neste ponto, não desconhecemos a presença de uma ordem previsível e incontestada que encontra o seu garante em decisões tomadas com base em julgamentos eficientíssimos que os "especialistas" realizam (Gouldner, 1978: 61), mas que se tem denunciado como um verdadeiro sofisma, pois fundamenta-se na crença de que se podem prever as actividades dos actores 
educativos em função de normas gerais e abstractas, inspiradas por um interesse geral, vazio de toda a substância. O regime de horário proposto pelo despacho 17387/2005, de 12 de Agosto, prevê o tempo que deve ser atribuído a cada actividade lectiva e não lectiva e, nesta, o tempo correspondente ao trabalho individual, ao trabalho de estabelecimento ou o tempo a despender com cada reunião. Reconhecer que as orientações normativas cumprem um papel integrador da acção organizacional enquanto estrutura comportamental, apoiadas na previsibilidade e calculabilidade da acção, não é para nós um problema; esse reside, em termos de análise organizacional, em saber em que medida essas mesmas orientações são corporalizadas no plano da acção organizacional.

\section{A autonomia relativa: outras decisões, outros modos de racionalidade}

Não podemos deixar de admitir a dimensão burocrática da escola e, nessa linha, é evidente que desconsiderarmos que existem decisões que transportam uma racionalidade a priori, que causam os efeitos desejados e esperados, que são cumpridas e interpretadas do mesmo modo nas escolas (entenda-se pelos elementos que a constituem), seria incorrermos em erro, o que não invalida que não seja necessário relativizar o seu alcance. Não o fazer seria cair numa visão demasiado simplista que só reclama de uma única racionalidade, tecnicista e óptima, e que se imporia a todos os sujeitos. Apenas essa relativização possibilita considerar outras decisões que resultam de interpretações diferenciadas, que são exigidas por situações imprevistas e que são a evidência empírica de uma organização dotada, a nível interno, de alguma autonomia, a qual admite outros modos de racionalidade e que se fundam na ideia de que não existe uma única solução para o mesmo problema e que essa solução não é a melhor possível mas a mais satisfatória. Tal entendimento alicerça-se na reflexão relativamente ao que se compreende por decisão eficaz, pois esta não é, necessariamente, uma decisão irrepreensível, perfeita (se é que existem efectivamente), mas a "melhor" decisão no interior de uma determinada conjuntura - o que pressupõe que para o mesmo caso possam existir várias soluções e todas elas correctas, na medida em que todas produzem um resultado favorável. 
Todavia, se podemos afirmar que existem várias maneiras de sermos bem sucedidos, tal não isenta o sujeito decisor de optar considerando a solução que se apresenta como a mais vantajosa, de acordo com os objectivos perseguidos.

Este plano poderá não concretizar o modo de organização formal que a administração central produz e, nesse caso, não o reproduz, levando-nos a concluir pela ausência de uma atitude prevista e desejável, em termos de resposta, dos actores educativos a algo que emana do exterior. Portanto, diríamos que, em termos decisórios, se confrontam a organização projectada e a organização vivida. Em termos analíticos, trata-se, no fundo, de confrontar dois planos: um que considera o "plano das orientações para a acção organizacional" e outro que considera o "plano da acção organizacional" (Lima, 1998: 160).

Fomos percebendo que, na escola, se produzem muitas decisões nem sempre conformes com o previsto e, nessa medida, não poderiam encaixarse numa teoria explicativa exclusivamente burocrática, pelo que abalavam o quadro de orientação formal-legal, já que a organização escolar parecia funcionar, em grande parte, à custa de tais decisões alicerçadas a outros tipos de racionalidade. A acção dos actores educativos estava longe de poder ser, em termos absolutos, conotada com a previsibilidade, a certeza e regularidade que se esperaria na estruturação das decisões. Dávamos conta de que não era possível eliminar as incertezas e os acasos dos comportamentos e que estes se orientavam segundo formas de racionalidade diversas da prevista pelo modelo teórico adoptado. A pretensa rigidez comportamental que a racionalidade formal difundia era frequentemente abalada por outras racionalidades que se cumpriam na criatividade e no espírito de iniciativa. As decisões, enquanto "receitas" organizacionais, não eram as únicas a contribuir para o funcionamento da escola; a presença de outras decisões, que o sistema burocrático não era capaz de controlar, era também causa de estabilidade, apesar de ter origem na instabilidade.

\section{Um modelo teórico integrador de focalizações diversificadas}

Deixava de fazer sentido a ingénua visão de a escola estudada espelhar, à custa dos seus comportamentos, uma realidade de conformidade 
burocrática, totalmente reprodutora de um quadro de orientação formal-legal, reservado que estava um comportamento passivo, conformista e congruente com as solicitações aos actores. Desmoronava-se, assim, uma perspectiva da escola como organização puramente burocrática devido ao elevado número de casos anómalos que se realizavam à margem da burocracia centralizada do Ministério da Educação, que produziam uma realidade paralela.

Neste novo contexto, que emergia, era evidente a construção de representações subjectivas e a criação de sistemas de produção de sentido para justificar o modo de agir, admitindo uma esfera de autonomia relativa ao nível da organização. Aqui os actores educativos demonstram interesse pelas decisões e reivindicam outros modos de tomar essas decisões, contrariando a mono-racionalidade burocrática e dando espaço à expressão de racionalidades divergentes, situação que nos fazia reflectir nas palavras de Friedberg quando escrevia que:

(...) on ne puisse plus parler d'une décision 'rationnelle' sans s'interroger aussitôt sur les conditions de cette rationalité. Une décision n'est rationnelle que par rapport à une situation, à un état donné du système social de l'organisation (1988: 85).

Só um modelo teórico de análise que nos conduza no sentido de aliar o enfoque que compreende decisões e procedimentos formais como garante da preservação da ordem pré-estabelecida (ou seja, a perspectiva burocrática) e um outro que contemple uma outra ordem ao nível da acção organizacional, com outras decisões e outras estruturas, propiciada por uma autonomia relativa que a organização parece não conseguir eliminar e à qual a perspectiva da anarquia organizada não é indiferente ${ }^{4}$, nos podem fornecer uma visão integral da realidade organizacional. O confronto destas duas perspectivas possibilita traçar uma dinâmica de escola onde cabem modos distintos de racionalidade nos fenómenos decisórios, propiciando uma análise que compreende as articulações e desarticulações que se produzem entre a lógica da burocracia e a lógica da anarquia organizada enquanto princípios que estruturam comportamentos e processos organizacionais. Neste sentido, a dinâmica da escola resulta da convergência de lógicas ligadas tanto à racionalidade burocrática como à racionalidade da anarquia organizada, ou seja, a acção decisória tanto é conforme às imposições formais como rompe com elas, assumindo-se, desta feita, a presença de inconsistências e 
desconexões relativas nos modos de decisão, ordem contrária à da burocracia.

Todavia, nenhum dos modelos tem carácter de exclusividade, na medida em que a presença de um deles não significa a rejeição do outro, mas antes a sua coexistência - que, na acção organizacional, se realiza de modo "conjuntivo" se os actores obedecem ao estabelecido e decidem em conformidade com objectivos, estruturas e recursos, e de modo "disjuntivo" (Lima, op. cit., p. 162) quando a conexão é posta em causa e as decisões passam a incluir um outro modo de racionalidade. Fazer opções unívocas num ou noutro sentido é ficarmos condicionados a uma única via que não é favorável à heterogeneidade nem à complexidade do conjunto, é ignorar e negar a realidade.

Com efeito, os regulamentos e procedimentos centralmente definidos permitem, supostamente, melhorar o desempenho dos actores na execução das suas tarefas, o que, em termos de racionalidade, supõe uma adequação dos meios aos fins perseguidos na tentativa de garantir a máxima eficiência possível, e que o modelo racional-legal institui. Esta racionalidade formal é a priori, rompe com a espontaneidade na medida em que permite tornar previsíveis e controlados os comportamentos dos actores, transformando-os em conformistas, em meros cumpridores do estabelecido, ao mesmo tempo que garantem a convergência da política adoptada e, nesse sentido, torna-se o seu instrumento de concretização. Aos actores não é reconhecida qualquer margem de autonomia, restando-lhes o respeito a essas decisões e responder pela sua execução, o que o aspecto instrumental da monoracionalidade configura 5 .

Considerar unicamente as decisões formais, em termos de análise organizacional da escola, afigura-se a um registo normativo mais congruente com considerações da ordem do dever ser regulamentado pela administração central, em prejuízo daquilo que os actores educativos possam julgar dever ser ou daquilo que é.

Se o intuito é privilegiar o plano da acção organizacional, a representação dos actores, devemos ter em conta um outro tipo de decisões enformadas pela anterior e por outras racionalidades, porém de mais difícil percepção, pois os seus contornos são de âmbito não oficial, ou seja, não estão previstas oficialmente pela organização mas são nela produzidas - 0 
que é revelador da autonomia de que os actores educativos dispõem. São decisões clandestinas, ou, utilizando a terminologia de Lima, diremos que são ocultas pelo facto de exigirem um maior esforço de detecção por parte daqueles que não pertencem à organização, pois as fontes documentais nem sempre as contemplam, de onde se depreende o seu carácter reservado e encoberto. Podem expressar um tipo de racionalidade decisória de cariz conjuntural e não generalizável a toda a organização. Com efeito, manifestam-se em situações ocasionais, como resposta a determinadas finalidades que a organização oficialmente não declara ou que são adoptadas a título particular pelos actores organizacionais, numa clara evidência de que no interior da organização se decide em função de interesses comuns mas também discordantes e controversos. De resto, o seu acontecer resulta das relações que os actores mantêm entre si enquanto prática dialógica que é portadora de visões diversas, o que supõe que as decisões também possam encerrar uma racionalidade de satisfação.

Ainda a distinguir estas decisões das anteriormente consideradas, assinala-se o diferente grau de estruturação - que, neste caso, tem relação com o processo que as originou. Se a racionalidade a priori das decisões formais encerra um processo cujo esquema é altamente linear, em que todos os momentos são sequenciais e não admitem qualquer desvio - o que evidencia uma linearidade simples - , já a racionalidade de satisfação das decisões obedece a um esquema que pode ser linear ou semi-linear, na medida em que são decisões que pressupõem interacção com o que as rodeia 6 e se pautam por requisitos que podem ser opostos aos determinados formalmente.

\section{Das decisões impostas às decisões construídas}

Ao transitarmos para o domínio daquilo que é, e que é manifesto pelos comportamentos decisórios efectivos dos actores educativos - de resto, aspecto sem o qual a análise organizacional não ficaria completa transitamos igualmente para decisões que podem encerrar uma racionalidade de tipo a posteriori que rompe com o esquema mecanicista e simplista da linearidade, em que a relação causa e efeito só se descortina após a consumação da decisão, motivo pelo qual é retrospectiva, e supõe modos alternativos de atingir com sucesso os objectivos. 
É neste enquadramento que se desenham outros tipos de racionalidade em oposição àquela que é imposta pela organização, pois também é aqui que se reconhece a possibilidade de existir uma relativa margem de autonomia que proporciona aos autores uma actuação decisória conforme às suas necessidades, expectativas e reflexões, convertendo a organização num espaço que não impede a concretização dos objectivos dos actores educativos, e deste modo contrariando e denunciando as contradições inerentes a uma racionalidade que universaliza e que supõe uma optimização.

Das decisões que a organização impõe (formalmente) aos actores, transitamos para as decisões que os actores produzem e que impõem à organização. A existência destas últimas deve-se muito mais ao interesse que os actores demonstram em encontrar uma solução concreta, subordinada a princípios contrários aos preconizados pela racionalidade formal, ou simplesmente encontrar uma solução que não tenha sido prevista, do que à existência de problemas 7 .

À semelhança de Simon, consideramos a "racionalidade de satisfação" (1989: 47) mais congruente com as capacidades humanas e o indeterminismo circunstancial. Todavia, a análise organizacional da escola, ao realizar-se por referência a um modelo que contempla o plano da acção organizacional efectiva ou realizada, incide sobre a realidade autêntica que os comportamentos decisórios dos actores, as regras praticadas e as estruturas manifestas concretizam. O domínio daquilo que é expressa uma operatividade por referência a vários modos de racionalidade, inclusivamente a priori. Com efeito, este é o espaço privilegiado para apreender o alcance de uma decisão cuja racionalidade se justifica retrospectivamente, ou seja, a posteriori. Assim, só após a concretização da acção os actores estão em condições de realizar uma hermenêutica que lhes permite a sua reconstrução, e isto se for alvo de averiguação. Apenas nesse caso se poderão descobrir as possíveis desarticulações entre intenções e concretizações como apanágio da provável falta de intencionalidade de uma acção e da solução encontrada ${ }^{8}$, mas que permite ajustamentos localizados sem prejuízo para a restante organização.

A análise que considera o plano da acção organizacional é capaz de desvendar e desmistificar a ideia de que as escolas, enquanto organizações, operam e são de igual modo. As marcas distintivas que as escolas possuem 
resultam de comportamentos decisórios também contrários e paralelos, nos seus modos e princípios de racionalidade, aos instituídos pelo poder central. Com efeito, os actores educativos, em grau diverso, obedecem (ou não) ao estabelecido, e estamos seguros de que nenhuma escola se mantém somente à custa de uma única ordem.

Decerto não ignoramos que as decisões impostas sejam objecto de atenção e obediência por parte dos actores educativos. Em termos genéricos, podemos afirmar que é o cumprimento de algumas das grandes decisões emanadas pelas instâncias superiores que torna possível encontrar um padrão comum a todas as escolas, apesar dos professores serem outros. $O$ funcionamento das escolas rege-se por grandes linhas orientadoras que estabelecem os objectivos da docência, o corpo curricular e respectivos conteúdos, a metodologia, a carga horária e sua distribuição, os critérios de avaliação a adoptar, a constituição dos órgãos e as competências atribuídas. Porém, estes mesmos órgãos não se encontram totalmente enclausurados nas normas impostas pelo sistema. Com alguma frequência, produzem determinadas decisões quanto à avaliação dos alunos, por vezes expressivas e integradas na sua realidade, outras relativas à distribuição dos tempos lectivos, outras ainda sobre os modos e procedimentos a adoptar nas vigilâncias de exames, ou mesmo em relação às viagens de estudo. Admitese claramente a existência de decisões não formais produzidas no interior da própria escola, como o atestam alguns documentos escritos, que visam outras soluções e outros comportamentos à margem das orientações formais-legais. Idêntico cenário acontece na sala de aula, espaço propício à ocorrência de certas decisões informais pelo "isolamento" em que o professor se encontra, em que define algumas regras contrárias às estabelecidas e age em consonância com as suas crenças, necessidades e objectivos, como o mostram a avaliação das actividades lectivas e o modo como decide em função de determinados comportamentos realizados pelos alunos, contrariando o instituído formalmente ou as deliberações dos órgãos da escola ${ }^{9}$. De resto, o conhecimento dessas decisões restringe-se a esse mesmo espaço, não sendo possível detectar a sua existência através de qualquer fonte documental, o que torna difícil o seu reconhecimento.

Admitir a existência de múltiplas racionalidades, ou o choque de racionalidades que as decisões integram, concorrentes e dissonantes entre si, 
rompe com a exclusividade da ordem burocrática, só possível porque se recorre a um modo de focalização diversificado que inclui o registo normativo, interpretativo e descritivo. Neste sentido, os comportamentos organizacionais são apreendidos enquanto consequência do que é estabelecido formalmente, mas também como resultado de acções concordantes com decisões de âmbito não formal e informal e, ainda, de decisões praticadas ou "actualizadas". De acordo com as diferentes focalizações, será possível detectar diversos tipos de racionalidades decisórias que permitem que a escola seja percepcionada enquanto locus de confluência de multiracionalidades.

\section{As multiracionalidades das decisões no contexto da organização escolar}

São as práticas que descortinam as racionalidades operantes ou actualizadas, isto é, que caracterizam o efectivo comportamento decisório dos actores educativos; e que serão classificadas de acordo com a selecção dos seguintes critérios: 1) Processo; 2) Requisitos; 3) Soluções; 4) Objectivo.

\section{1 - Processo}

A função da decisão, que se confunde com a sua razão de ser, é poder desencadear a continuidade da acção (entenda-se a acção futura). Tomar uma decisão pressupõe a utilização de um determinado procedimento que nos conduz à eleição de uma alternativa. É, no fundo, responder à questão de como tomamos as nossas decisões sem excluirmos a possibilidade da existência de vários esquemas, os quais, por si mesmos, acusam uma racionalidade diferente. Os aspectos a destacar no âmbito do processo da tomada de decisões, e que a nosso ver melhor servem os nossos intentos, são o tipo de linearidade aplicada e os tipos de futuro previstos pelos agentesdecisores, de onde resulta uma racionalidade a priori, probabilística e a posteriori.

\section{1 - Racionalidade a priori}

Releva da concepção clássica da tomada de decisão que pressupõe que entre a percepção do problema e a solução, ou seja, entre os dois pontos 
extremos da tomada de decisão, se estabelece uma cadeia contínua e lógica de actividades comportamentais - o que vai no sentido do carácter unificado do conjunto, que não admite nenhum tipo de desvio, rejeitando qualquer outra possibilidade de ordenação, princípio que se funda na ideia de que a realidade é igualmente linear, que é estática. Assim, supõe o acto de decisão isolado e constituído por um conjunto de fases bem delimitadas que se sucedem de maneira exacta e necessária, de onde se conclui que o actor educativo parece estar equipado com uma única bagagem de respostas determinísticas e absolutas. Esta conceptualização de racionalidade só faz sentido porque todas as consequências da decisão são inteiramente previsíveis com alto grau de exactidão, de onde releva o seu carácter a priori. Estamos na posse do conhecimento claro das ligações entre causa e efeito, aspecto que faz da decisão uma questão inequívoca, redundando num elevado controlo da realidade que se compreende como estática, mecânica e rígida. Diríamos estar em presença de uma racionalidade simplista.

\section{2 - Racionalidade probabilística}

A linearidade inclusa neste pressuposto de racionalidade é entendida de modo ténue pela dificuldade em se perceber nitidamente os seus limites, mas ainda possuindo o conhecimento de todas as alternativas e de todas as consequências, só havendo dúvidas sobre qual a decisão que será tomada daí o seu carácter probabilístico. Assim, tanto o fim como o início são incertos, apesar de se manter entre estes extremos a mesma cadeia contínua de actividades do esquema clássico, o que confere a este processo uma objectiva estruturação, um fraccionamento linear do processo, fiel à teoria clássica. É uma racionalidade caracterizadora de uma decisão que reconhece que está contaminada pelo entrecruzamento de outras decisões, ainda que se admita que se conhecem as causas e os efeitos; as previsões quanto ao futuro são razoavelmente correctas, ou seja, as consequências são previsíveis. Estamos em presença de uma racionalidade que emerge em contexto de negociação de jogos de influências, que não permite a linearidade absoluta do processo.

\section{3 - Racionalidade a posteriori}

Apesar de identificados, os momentos constitutivos do processo de tomada de decisões têm a sua ordem subvertida, admitindo mesmo a 
possibilidade de combinação de alguns e, portanto, a sua descontinuidade, abalando o esquema clássico da linearidade que, dentro da sua lógica, perspectiva este modo como um desvio. É uma linearidade - que não é distinta quanto às fases que compreende e à transição de uma fase para a outra, reveladora de uma certa espontaneidade. O termo do processo é tomado pelo seu início, de modo que a ligação do sujeito à sua acção não seja de um vínculo de causalidade mas sim de expressividade, porque a relação entre causa e efeito só se desvenda após a execução da decisão - aspecto que enfatiza a ideia de que a descoberta das intenções da acção é realizada de modo retrospectivo, ou seja, a posteriori. É uma racionalidade que, quanto ao futuro, integra uma dimensão de abertura, pois as consequências da decisão são imprevisíveis. Neste sentido, a situação de decisão, que se assume como complexa, pode identificar-se com uma acção de exploração, de desenvolvimento de significados; uma situação que não prevê o controlo sobre o futuro, tanto quanto não impede o sujeito de o pensar, já que considera a interacção com o que o rodeia.

\section{2 - Requisitos}

A racionalidade não diz, exclusivamente, respeito ao pensamento, mas a racionalidade de uma decisão também pode estar associada à acção que lhe é inerente, e que os meios e os fins permitem caracterizar. De facto, são esses requisitos que vão permitir identificar a racionalidade da decisão, pela importância que vai ser conferida a um, em detrimento do outro, ou a ambos. Meios e fins são dois aspectos elementares na abordagem da problemática da racionalidade, porque será sobre eles que recairá a nossa atenção quando tentarmos conjecturar acerca da sua verdadeira natureza. A racionalidade pode, assim, apresentar-se com duas caras - pela perspectiva dos meios, quando é o reflexo de uma preocupação pragmática relativa à eficiência do processo; pela perspectiva dos fins, quando a preocupação incide sobre o produto - , apesar de alguns autores serem de opinião que, em termos reais, não há uma separação completa entre meios e fins. Neste âmbito distinguiremos entre racionalidade instrumental e substantiva.

\section{1 - Racionalidade instrumental}

Definida por Weber como uma racionalidade que compreende a relação entre meios e fins, com referência à relação entre causa e efeito, e 
com uma preocupação fundamental pela excelência dos métodos na procura da solução óptima, em comparação com os meios utilizados para se atingirem os objectivos pretendidos (1999: 38). É, neste sentido, uma racionalidade técnica alicerçada na ideia do esforço mínimo e do máximo rendimento, princípio em que se baseia a racionalidade económica (id. ibid.: 12). Nesta linha de pensamento, e parafraseando Simon, diremos que, entre as várias alternativas possíveis que permitem a consecução dos objectivos, a nossa escolha deve recair sempre sobre a que custa menos (1971: 40). Porém, estes fins não são objecto de reflexão; são, simplesmente, nunca se pondo em causa os valores em nome dos quais se actua ou a preferência desse fim - daí ser uma racionalidade que só incide no como e com que meios se pode atingir determinado objectivo. O plano dos fins vê-se, assim, votado à indiferença, em grau semelhante à exclusão da dimensão afectiva, pelo receio de que possa contaminar a procura da melhor solução aquando da tomada de decisões.

\section{2 - Racionalidade substantiva (substancial para Morgan)}

É uma forma de racionalidade que se concretiza no esforço de tornar efectiva a presença dos meios e dos fins de modo simultâneo, pelo relevo que Ihes é conferido, motivado pela necessidade de se questionar reflexivamente os objectivos da decisão, visando a sua legitimidade. Ao exigir a presença destes dois requisitos, supõe uma racionalidade enformada por uma orientação axiológica, que incide sobre o que devemos ter como preferível ou prioritário, e uma orientação instrumental, porque não nega a preocupação sobre a eficácia de um processo que aspira à realização de uma finalidade considerações que, na óptica de Morgan, se sintetizam na necessidade de encontrar decisões que sejam norteadas por esclarecimentos de toda a situação (1996: 40). Partindo do pressuposto de que, ao agente da decisão, nem os meios nem os fins podem ser indiferentes - porque, para além de serem dois requisitos que fazem parte integrante da racionalidade, conferemIhe unidade - não podemos abdicar de nenhum deles. De facto, utilizar meios adequados para alcançar objectivos inconvenientes e inoportunos é tão desconforme como usar meios desadequados para atingir objectivos legítimos. É uma racionalidade que tem por propósito fundamental legitimar a decisão, na medida em que se indagam os seus porquês. 


\section{3 - Soluções}

Por definição, a acção racional é aquela que se fundamenta nas nossas razões mais fortes, de onde deriva que a resolução é a melhor solução que podemos escolher porque é aquela que garante os melhores resultados. Deste modo, uma decisão é racional sob o ponto de vista da solução que encerra, a qual pode ser perspectivada de acordo com o corpus de informação conseguido, os valores que a constituem e a capacidade do agente para tomar decisões correctas - circunstâncias que deixam antever uma racionalidade olímpica/óptima, limitada/satisfatória e hermenêutica.

\section{1 - Racionalidade olímpica/óptima}

A solução prevista contém os germes de um ser humano que não existe na realidade, um super-homem com capacidades infinitamente superiores às que são próprias dos homens e das mulheres da vida real consideração que justifica a conceptualização de "olímpica", proposta por Simon. É uma racionalidade que se funda no pressuposto de que o sujeito está na posse de toda a informação absolutamente necessária relativa ao curso da acção e à possibilidade de prever todas as consequências daí resultantes, como se fosse capaz de absorver toda a incerteza da realidade. Ou seja, o decisor possui uma capacidade ilimitada para recolher e tratar a informação, como se pudesse accionar um raciocínio sinóptico "que lhe permite proceder a um exame comparativo ao mesmo tempo exaustivo e simultâneo de todas as soluções possíveis com as suas consequências prováveis" (Friedberg, 1993: 45). Conhecimento completo e antecipado, a opção por uma alternativa entre todos os comportamentos alternativos configura esta racionalidade como utópica, porque inalcançável.

O problema da racionalidade é sensível ao da informação, implicando, portanto, que a tomada de decisões esteja dependente da quantidade de informação que temos sobre determinada situação. Esta dependência é tal, que o simples acréscimo de informação à que já possuímos pode alterar o nosso sentido de óptimo. A racionalidade óptima, que Simon associa à racionalidade olímpica, pressupõe o máximo de utilidade porque a decisão é orientada segundo soluções que são simplesmente as óptimas, que têm em conta absolutamente tudo aquilo que é indispensável - daí que esta 
racionalidade esteja relacionada com a optimização absoluta, dando sentido à ideia de que o idealmente racional será fazer o óptimo.

\section{2 - Racionalidade limitada/satisfatória}

O conceito de racionalidade limitada, que encontramos na obra de Simon, subentende a existência de factores que limitam a própria racionalidade. Neste enquadramento, a racionalidade é sempre matéria de optimização relativa porque a nossa capacidade, o nosso espírito é limitada/o o que vai ao encontro da ideia de que a racionalidade é arte dos possíveis, de fazermos o melhor que é possível em certas circunstâncias, inclusivamente as cognitivas (Simon, 1989: 47). Desta limitação releva um conhecimento fragmentado das condições que circundam a acção e a impossibilidade de determinar todas as consequências de forma antecipada, sendo que a esta visão está associado um conhecimento limitado quer das alternativas, quer das suas repercussões. Esta ideia de racionalidade está alicerçada no pressuposto de que seria impossível sermos racionais se tal implicasse termos informação completa - o que se transformaria em algo totalmente irrelevante e sem sentido para o ser humano, que não opera no âmbito de circunstâncias ideais mas reais. Postula-se aqui, contrariamente ao raciocínio sinóptico, um raciocínio sequencial, mais concordante com a complexidade dos processos mentais. No fundo, é considerarmos que esta racionalidade subentende, nas palavras de Friedberg, um comportamento próximo de "uma adaptação activa e razoável a um conjunto de constrangimentos e de oportunidades percebidas no seu contexto de acção" (1993: 46).

A proposta de racionalidade satisfatória de Simon situa-se num quadro realista e alcançável, ou seja, orienta-se por resoluções que são as melhores ao nosso alcance tendo em conta tudo aquilo que é relevante em correspondência com o que nos é possível realizar em certas circunstâncias - o que assenta no reconhecimento de uma maximização que nunca é absoluta. Diríamos que é o óptimo praticável e circunstancial face à informação disponível e incompleta que temos ao nosso alcance; é o nosso melhor possível, apesar de não termos garantias absolutas do êxito - pelo que jamais podemos estar seguros de que continuaria a ser o óptimo se tivéssemos outra informação, ou se esta fosse mais completa (Recher, 1993: 44). 
Portanto, a solução encontrada não é absolutamente a melhor, nem mesmo quando em causa estão os critérios de satisfação do decisor, porque nada invalidaria que a escolha fosse outra se a procura continuasse. Neste caso, diremos que a solução é a melhor considerando todas as outras que haviam sido examinadas, o que exclui a possibilidade do decisor optimizar e maximizar. Diríamos estar em presença de uma perspectiva de racionalidade que, por ser mais modesta, ou seja, menos pretensiosa, é mais realista.

No entanto, a conceptualização de satisfatória ultrapassa o âmbito cognitivo e assenta em decisões que resultaram de acordos que não foram alheios à presença de preferências, interesses e subjectividades de cada actor educativo, motivo pelo qual a solução encontrada se configure como aceitável - querendo com isto dizer que é uma solução que, não sendo a preferida por qualquer das partes implicadas no processo, é a menos má.

\section{3 - Racionalidade hermenêutica}

Esta racionalidade, proposta por Gadamer, tem preocupações com a certeza e verdade do conhecimento e concretiza-se num constante perguntar e responder, numa permanente atitude argumentativa que se manifesta na capacidade de refutação, disponível a outros pontos de vista (1984: 556). É uma racionalidade que se confunde com um projecto de permanente actividade concretizado na capacidade que o pensamento tem de indagar, no diálogo inter-subjectivo em que é manifesta a discussão argumentativa, e na crítica das convicções adquiridas. É a reflexão que auxilia na procura das possibilidades do conhecimento e a linguagem que se assume como meio por excelência desse conhecimento.

Este tipo de racionalidade, pelos contornos que adquire, tem paralelo com a racionalidade compreensiva proposta por Horkheimer, pelo reconhecimento da razoabilidade de qualquer acção (1973: 195), e com a racionalidade activa proposta por Sousa Santos, porque em trânsito, inquieta, desinstalada de certezas paradigmáticas (2002: 39). Racionalidade comunicativa, na peugada de Habermas, que se assume pela relação intercomunicativa do sujeito com a acção, com o mundo dos factos; que é feita através da mesma linguagem, assente numa moral universal liberta de constrangimentos e, por isso, autêntica, livre para criticar e problematizar - 
mas nem por isso infalível, porém visando a transformação dos interlocutores (1987: 36).

\section{4 - Objectivo}

As decisões, sejam elas quais forem, estão sempre ao serviço de um projecto que torna visível o seu alcance. Não só o conteúdo que incluem, mas também a forma que presidiu à sua produção, evidenciam o sentido que lhes está subjacente em termos de comprometimento e defesa dos actores educativos, no que respeita à sua autonomia e liberdade, numa alusão à problemática do poder. Desta feita, toda a decisão pode ser traduzida numa forma de acção, ao mesmo tempo que é inspirada em valores. Assim, a racionalidade assume o carácter de instrumentalizadora ou emancipatória.

\section{1 - Racionalidade instrumentalizadora}

Releva de uma decisão que não permite o desenvolvimento das capacidades de homens e mulheres e inviabiliza a sua acção decisória pela força do poder de outrem. Dispensa a opinião formulada por aqueles e recusa a entrada de considerações de outra natureza que não a economicista, que poderiam colocar em causa a lógica da reificação. As suas ideias, desejos e acções ficam balizadas por uma política já concebida e, assim, impede-se a construção de esferas de debate público - o que se converte numa situação de alienação para o sujeito porque incorpora valores anexados à eliminação de interesses conflituantes, reproduzindo uma perspectiva cultural comum e suprimindo as possíveis diferenças, no intuito de homogeneizar, de onde deriva o seu carácter de universalidade. Daqui se depreende que as relações são mobilizadas pela acriticidade e pela mecanização, que domesticam, em vez de cuidar da perfectibilidade do ser humano, acabando por o converter num simples executor, reduzido à condição de sujeito passivo.

\section{2 - Racionalidade emancipatória}

Em coerência com os princípios democráticos, esta racionalidade, preconizada por vários autores, dos quais destacamos Freire e Sousa Santos, apela ao fortalecimento do pensamento e da experiência humana concretizada pelas decisões que homens e mulheres produzem, sem que 
visem uma eficácia em prol de finalidades económicas (antes as questionando). É uma racionalidade de carácter mobilizador que se traduz numa esfera dialógica dos sujeitos e que é capaz de identificar os mecanismos de opressão, de controlo e de dominação que dificultam a revitalização da esfera pública. Pressupõe um sujeito ligado às condições da sua circunstância e assegura soluções expressivas face à realidade que se configura como diferente. Comprometida com a crítica e o questionamento dos discursos hegemónicos - só possível porque incita a uma cidadania verdadeiramente democrática, em que o ser humano se transforma em autor da sua própria história, o que reverte em favor da sua emancipação - , evidencia modos permeáveis ao princípio de intervenção concretizável através das decisões dos indivíduos, daí que se afirme pela dissolução de qualquer relação de poder autocrático.

\section{A escola: lugar de instrumentalização e de emancipação}

As multiracionalidades acontecem à medida que as actividades se realizam e que os actores organizacionais se relacionam entre si, podendo resultar de estratégias e de negociações cuja finalidade será sempre encontrar uma resposta, em forma de solução, para determinada situação decisória.

Os homens e as mulheres da vida real constatam a realidade à margem de uma imagem totalizadora e perfeitamente ordenada em conformidade com as decisões pré-definidas - que se traduziria, no que à escola diz respeito, numa configuração fixa e imutável. E se a racionalidade instrumental, que o modelo centralista compreende, objectiva o sujeito, existe a possibilidade de as decisões, de que eles próprios são os autores, encerrarem uma racionalidade mais comprometida com os valores e com as finalidades do acto de decisão ${ }^{10}$. Deste ponto de vista, o importante é não rejeitarmos o confronto entre as diferentes racionalidades que as decisões, em coerência com uma particular orientação, transportam.

$\mathrm{Na}$ verdade, uma racionalidade que se mostra isenta de qualquer resquício de erro exerce grande atracção nos actores educativos, mesmo porque está vinculada a decisões a que é preciso obedecer caso não se queira incorrer em actuações marginais, ou desviantes, em alguns casos 
passíveis de serem sancionadas. De resto, tais decisões são apresentadas como vinculadoras de valores e interesses consensuais. Contudo, a ocorrência de outras racionalidades, evidenciadas em outras decisões que também compõem a dinâmica organizacional e que confirmam o postulado de March de que "Organizations rarely do exactly what they told to do" (1991: 563), conduzem-nos a percepcionar este fenómeno à margem de acontecimentos meramente episódicos ou acidentais. Por ter uma existência continuada e usual por parte dos actores educativos - de onde se depreende que estes não se esvaziaram de si próprios no que respeita aos seus objectivos, interesses e expectativas (por vezes de aparência fluida, ambígua e contraditória) e não se negam enquanto detentores de alguma margem de autonomia - não podemos subestimar a sua importância quando em causa está caracterizar os comportamentos dos actores e a respectiva acção organizacional. Não é só o desconhecimento de certas decisões elaboradas pela administração central que motiva a emergência de racionalidades dissonantes, mas, essencialmente, o resultado fracassado de uma política de adaptabilidade que não conseguiu evitar o questionamento em prejuízo do conformismo, ou ainda o resultado de um encontro fortuito e surpreendente que não deixou espaço à ponderação mas que teve em conta a sensibilidade, a intuição, a emoção, os interesses e expectativas, a que a racionalidade formal se nega.

Estas racionalidades informais ${ }^{11}$, que sistematicamente deambulam pela organização, têm um grau de aceitação diferenciado que está em relação directa com o conteúdo que abrigam, que lhes confere um carácter mais humanista, e com a verificação de que existem outras vias e procedimentos que permitem o reconhecimento inteligente de situações decisórias bem mais importantes do que os cálculos que se podem efectuar. Trata-se de contrariar a natureza mecanicista dos comportamentos e reconhecer a importância de outros contributos, de natureza variada, repercutidos nas racionalidades dos actos decisórios. Apesar de mais modestas, porque mais realistas, estas racionalidades, com frequência, sustentam decisões que passam a vigorar nas práticas organizacionais, carregando, por vezes, um estatuto institucional e sendo constantemente reclamadas pelos actores como sintomáticas de uma autonomia que lhes é repetidamente recusada. 
Destaca-se, assim, o frequente combate dos actores à racionalidade formal através da produção de multiracionalidades, como se estivéssemos em presença de uma contenda em que as racionalidades informais se erguem contra a formal. A racionalidade formal, pese embora toda a instrumentalidade de que se reveste, traduz uma universalidade que assegura uma igualdade representativa dos direitos e dos deveres e incorpora receitas que são preferíveis a soluções produzidas por outros, a quem não se reconhecem qualidades suficientes, pois raramente redundam em êxito ${ }^{12}$. As racionalidades presentes em decisões efectivadas pelos actores educativos são representativas dos contornos de incerteza e de risco a que a realidade não escapa e evidenciam um comportamento que não é compatível com paralisias que uma análise demasiado minuciosa pode conter, o que não invalida que incluam os mesmos propósitos e a mesma formalização das anteriormente citadas. Acentuam e explicam a importância de avaliações individuais, já que são racionalidades marcadas pela subjectividade dos actores e pelo conhecimento limitado da situação, e pressupõem um ajustamento dinâmico à situação, que por vezes resulta de preferências produzidas pela situação da escolha. No interior desta lógica, a optimização absoluta é um conceito vazio de sentido e assume-se que podem existir vários meios para se chegar a determinado fim, tanto quanto se assume que não há uma solução única, mas várias. De resto, a racionalidade das decisões não reside somente na maneira como se tomam, mas também no conteúdo que transportam. Recorde-se que assumir a existência de multiracionalidades é desmistificar o centralismo administrativo enquanto mecanismo absoluto de coação, contraposto à ideia de sujeito autónomo, comprometido e permeável a desafios situados na sua trajectória.

\section{Conclusão}

Esta proposta resultou da apreciação de diversas perspectivas estudadas, na pretensão de que seja útil enquanto ponto de partida para o estudo das diferentes racionalidades inclusas nas decisões dos professores da escola secundária. Será a base de que nos munimos no pressuposto de que, dentro dos possíveis, poderá dar conta da multiplicidade e complexidade de situações decisórias que acontecem na escola - fenómeno que, por si só, encerra uma dimensão política pelo sentido de democracia que, a nosso ver, 
é central, e que, à semelhança dos conceitos de descentralização e autonomia, se constitui como uma conquista, e não como um dado adquirido, porque, à semelhança do que acontece com a participação ${ }^{13}$, a natureza da decisão reside na sua prática (o contrário obrigaria a considerá-la apenas como letra morta). As decisões praticadas não dispensam, para a sua caracterização, a alusão às diversas categorias dos actores que os diferentes órgãos evidenciam, pois só assim será possível recusarmos um quadro monolítico de racionalidade suportado por visões unitárias da organização escolar.

A organização escolar, sob este prisma, será um espaço de convergência de ordens diversas e, nesse sentido, por parte dos actores educativos, abrange comportamentos de mera observância e de manifesta criação, de acomodação e de transformação, de aceitação e de resistência. Este é o mote que permite defini-la, no que concerne às racionalidades, enquanto lugar de instrumentalização e de emancipação.

\section{Notas}

1 Escreve Licínio Lima, no âmbito do poder e dos governantes: "É que logo compreenderão que conquistaram um poder que, para se afirmar como democrático de acordo com as suas premissas, terá de ser redistribuído e partilhado, em parte devolvido e transferido, assim os deixando menos poderosos. Ficarão, então, mais dependentes do diálogo, da discussão e da negociação, por vezes forçados a despender mais tempo e a consumir mais energias, sujeitos a decisões satisfatórias mas não consideradas ideais, obrigados a compromissos face a projectos que consideram essenciais e a acções que entendem como prioritárias e indispensáveis" (2000: 49).

2 A este propósito lembra Lima que "A democratização da administração, nos seus diferentes níveis, não é somente um factor facilitador, ou instrumental, face à construção de uma escola democrática e autónoma; é também um valor em si mesmo, que só pela sua afirmação e actualização continuadas pode permitir e reforçar a democratização das estruturas e dos modos de gestão escolares" (id., ibid.: 46).

3 Intentos que, na óptica de Georges Lapassade, são representativos de um verdadeiro disfuncionamento promovido por algumas das sua características, das quais salienta uma comunicação que se realiza do topo para a base, ocultação do autor da decisão, dificuldade em conhecer onde, quando e como se decide (s.d.: 24-30).

4 Não que o modelo de anarquia organizada se deva entender enquanto modelo de irracionalidade por oposição à burocracia se tomada enquanto modelo de 
racionalidade. Na verdade é antes um modelo menos racionalista pelos princípios da racionalidade instrumental, que não evidencia uma relação de causa e efeito porque a tomada de decisão é realizada em condições bem diferentes das definidas pelo modelo burocrático, quer em termos de poder, de valores e de objectivos (Darling-Hammond, Wise \& Pease, 1983: 236).

5 Esta racionalidade caracteriza-se por comportamentos que suscitam formalismo e controlo e uma "estruturação racionalizada explícita tanto das pessoas como da actividade" (Jepherson \& Meyer, 1999: 281).

6 Licínio Lima considera neste enquadramento o nível intermédio e o nível profundo, fazendo corresponder ao primeiro as regras não formais e ao segundo as informais, com um grau de estruturação diferenciado. As primeiras apresentam um relativo grau de estruturação, que pode viabilizar a sua fixação em documentos escritos, e circulam com relativa visibilidade na organização; as segundas carecem mesmo dessa estruturação, o que lhes retira a possibilidade de tomar forma escrita, e a sua visibilidade nem sempre é percebida por todos os actores, embora as decisões, com alguma frequência, permitam inferir a sua existência (1998: 166-167).

7 A existência de problemas, por si só, não é condição suficiente para que possam emergir outras racionalidades; a vontade do actor em os solucionar é que se revela como condição necessária a que essas racionalidades se mostrem.

8 Na linha de Karl Weick, podemos considerar que, a nível funcional, a articulação débil (loose coupling) pode ser um fenómeno de considerável importância para o funcionamento diário da organização.

9 Relativamente a esta possibilidade do professor produzir decisões na sala de aula, escreve Claude Lefort: "É certo que se encontra submetido a um poder administrativo. A sua sorte depende das decisões tomadas ao nível da direcção de um serviço de Ministério. Mas ele escapa, em larga medida, a esse poder: o conteúdo da sua actividade só é determinado numa medida extremamente parcial pelos serviços dos ministérios" (s.d.: 272-273).

10 Esta questão não deixa de ter semelhanças com a problemática da Produção e Reprodução de Regras: Normativismo e Infidelidade Normativa, desenvolvida por Lima, que acentua o facto de os próprios actores educativos, devido a condicionamentos diversos, nem sempre reproduzirem na perfeição as normas consagradas - sendo que, neste caso, deve-se considerar a sua produção localizada. Obviamente que quando assumimos que os actores educativos tomam decisões alternativas às existentes, e por isso incorrem numa infidelidade, ou são obrigados a tomar decisões que preencham os espaços que ficaram por regular, estamos a conjecturar para estas um tipo de racionalidade diferente da formal.

11 Utilizamos aqui o termo "informal" para designar outras formas de racionalidade contrárias à racionalidade clássica.

12 Esta posição pode ser articulada com a que reconhece a importância da autonomia quando esta só implica um acréscimo de autonomia para uns e não para outros, nomeadamente aquele de que a comunidade e o poder poderiam usufruir.

13 Escreve Licínio Lima: "A participação só existe verdadeiramente como prática, de resto como a democracia, e pelo facto de ter sido formalmente consagrada uma vez, mesmo ab initio, ela não se transforma num princípio irreversível, 
eventualmente constitutivo daquilo que alguns autores entendem, estranhamente, por 'constituição genética' ou 'genotipo' da organização" (1998: 195).

\section{Referências}

Darling-Hammond, L., Wise, A., \& Pease, S. (1983). Teacher evaluation in the organizational context: A review of the literature. Review of Educational Research, v. 53, n. 3, 285-328.

Freire, P. (1967). Educação como prática da liberdade. Rio de Janeiro: Paz e Terra.

Friedberg, E. (1988). L'analyse sociologique des organisations. Paris: Grep.

Friedberg, E. (1993). O poder e a regra. Dinâmicas da acção organizada. Lisboa: Instituto Piaget.

Gadamer, H.-G. (1984). Verdad y método. Fundamentos de una hermenéutica filosófica. Salamanca: Ediciones Sígneme.

Gouldner, A. W. (1978). Conflitos na teoria de Weber. In E. Campos (Org.), Sociologia da burocracia (pp. 59-67). Rio de Janeiro: Zahar Editores.

Habermas, J. (1987). Técnica e ciência como ideologia. Lisboa: Edições 70.

Horkeimer, M. (1973). Critica de la razón instrumental. Buenos Aires: Ed. Su.

Jepherson, R., \& Meyer, J. (1999). El orden público y la construcción de las organizaciones formales. In W. W. Powel \& P. J. Dimmagio (Coord.), El nuevo institucionalismo en análisis organizacional (pp. 261-293). Mexico: Fondo de Cultura Económica.

Lapassade, G. (s.d.). Burocracia, burocratismo, burocratização. In A Burocracia. Lisboa: Socicultur.

Lefort, C. (s.d.). O que é a burocracia. In A Burocracia. Lisboa: Socicultur.

Lima, L. (1998). A escola como organização e a participação na organização escolar: Um estudo da escola secundária em Portugal (1974-1988). Braga: Universidade do Minho.

Lima, L. (2000). Reformas educacionais em Portugal e no Brasil. Belo Horizonte: Edições Autêntica.

March, J. (1991). Décisions et organisations. Paris: Editions d'Organisations.

Morgan, G. (1996). Imagens da organização. São Paulo: Atlas.

Recher, N. (1993). La racionalidad. Una indagación filosófica sobre la naturaleza y la justificación de la razón. Madrid: Editorial Tecnos.

Santos, B. Sousa (2002). A crítica da razão indolente. Contra o desperdício da experiência (vol. I). Porto: Edições Afrontamento.

Simon, H. (1989). A razão nas coisas humanas. Lisboa: Editora Gradiva.

Simon, H. (1971). Comportamento administrativo. Rio de Janeiro: Fundação Getúlio Vargas.

Weber, M. (1999). Economia e sociedade. Fundamentos da Sociologia Compreensiva (vol. I). Brasília: Editora Universidade Brasília. 


\title{
MULTIRATIONALITY IN THE ORGANISATIONAL CONTEXT OF SCHOOLS
}

\begin{abstract}
The study of rationality in educational organisations, particularly schools, has decision making as an underlying problem. The denial of a monistic and absolute conception of rationality opens up the possibility of distinguishing among various forms of rationality. Such a possibility presupposes a multiple focused framework in the study of schools viewing both bureaucratic and anarchic models as a theoretical account that integrates differing sorts of power.
\end{abstract}

Keywords

Decision; Bureaucratic rationality; Multirationality

\section{LES MULTIRATIONALITÉS DANS LE CADRE DE L’ORGANISATION SCOLAIRE}

Résumé

L`étude de la rationalité dans le cadre de l’organisations éducatives, notamment à l'école, a le fond de la problématique des décisions dans l’éducation et dans l’enseignement et l’identification des intérêts, des logiques et des objectifs qui leur sont sous-jacents. Le refus d'une conception moniste et absolue met nous devant la possibilité de distinguer parmi différentes formes de rationalité. Cet objectif fait supposer une étude multi-centrée dans l’école en considérant, en termes d’analyse et de façon articulée, les modèles bureaucratique et anarchique en concevant un appareil conceptuel qui est lié à létude proposée sur les multirationalités qui intègrent les décisions qui mettent en évidence les différentes formes de pouvoir.

Mots-clé

Décisions; Rationalité bureaucratique; Multirationalités

Recebido em Janeiro, 2010

Aceite para publicação em Maio, 2011

Toda a correspondência relativa a este artigo deve ser enviada para: mjcc@utad.pt 